\title{
Conductivity percolation in carbon-carbon supercapacitor electrodes
}

\author{
N.L. Wu*, S.Y. Wang \\ Department of Chemical Engineering, National Taiwan University, 106 Taipei, Taiwan ROC
}

Received 5 February 2002; accepted 25 April 2002

\begin{abstract}
Composite electrodes which comprise a non-conductive activated carbon of large surface area $\left(1420 \mathrm{~m}^{2} \mathrm{~g}^{-1}\right)$ and a conductive carbon black (CB) of small surface area $\left(220 \mathrm{~m}^{2} \mathrm{~g}^{-1}\right)$ have been prepared and studied for their capacitive properties in aqueous $\mathrm{KOH}$ and $\mathrm{Na}_{2} \mathrm{SO}_{4}$ electrolytes. For either electrolyte, maximum capacitance exists at the composition believed to correspond to the percolation threshold for $\mathrm{CB}$, the conductive phase. At a CB content less than the threshold, the capacitance is limited mainly by the electronic resistance on the electrode side. The interfacial surface area becomes the limiting factor as the threshold is exceeded. A maximum capacitance of $108 \mathrm{~F} \mathrm{~g}^{-1}$ at a voltage sweep rate of $20 \mathrm{mV} \mathrm{s}^{-1}$ is obtained in $1 \mathrm{M} \mathrm{KOH}$ aqueous electrolyte with a CB content of $25 \mathrm{wt} . \%$ (or $\sim 14$ vol.\%). (C) 2002 Elsevier Science B.V. All rights reserved.
\end{abstract}

Keywords: Electrochemical capacitor; Carbon composite electrode; Conductivity; Percolation; Pose diffusion resistance

\section{Introduction}

Carbonaceous materials are important electrode constituents in supercapacitor devices. They have been employed either as the sole electrode component in an electric doublelayer capacitor (EDLC) [1-7], or as part of composite electrodes that contain pseudocapacitive materials, such as $\mathrm{RuO}_{2}$ [8-10]. There currently exist carbonaceous materials which possess a variety of microstructural and electrical properties, and have a wide range of cost. Combination of these materials provides a flexible way to optimise the capacitor based on performance and cost considerations. Understanding the interplay between the overall properties of such a composite electrode and the characteristics of its carbon constituents is a key to the optimisation process.

In terms of kinetic considerations, for instance, high electrode conductivity and large pore size are important and can be achieved by carbons with a high degree of graphitisation. The high-temperature graphitisation process, nevertheless, typically leads to a significant loss in specific surface area [11] and, hence, to low capacitance. Although graphitic materials such as carbon nanotubes have both high conductivity $\left(\sim 1 \mathrm{~S} \mathrm{~cm}^{-1}\right)$ and large surface area $\left(>1000 \mathrm{~m}^{2} \mathrm{~g}^{-1}\right)$, they are in general of much higher cost

\footnotetext{
* Corresponding author. Tel.: +886-22-3635230; fax: +886-22-3623040

E-mail address: nlw001@ccms.ntu.edu.tw (N.L. Wu).
}

than non-graphitic activated carbons, which are also of large surface area but poor conductivity.

Aiming for a carbon EDLC of low cost, the present work has focused on composite electrodes that contain non-graphitic activated carbons as the main source for providing the needed charge-storage interfacial areas, along with conductive carbon black (CB) for improving electrode conductivity. Emphasis is placed on determining the optimum content of $\mathrm{CB}$ for maximum capacitance and also on understanding the general electrochemical behaviour of such composite electrodes.

In brief, it is found that the capacitance of the composite electrode depends strongly on composition. Maximum capacitance is obtained at the composition that corresponds to the percolation threshold of the conductive component (the CB). The results may also have strong implication in other electrochemical cells where conductive materials are intentionally added for improving electrode conductivity.

\section{Experimental}

Electrochemical capacitive properties were characterised by cyclic voltammetry (CV) analysis using an electrochemical analyser (Eco Chemie PGSTAT30) and a plane-type capacitor cell. The electrodes had a $1 \mathrm{~cm} \times 1 \mathrm{~cm}$ active area, a thickness of $750 \mu \mathrm{m}$. Titanium mesh served as the currentcollector. Aqueous solutions of $1 \mathrm{M} \mathrm{KOH}$ and $1 \mathrm{M} \mathrm{Na}_{2} \mathrm{SO}_{4}$, 
respectively, were used as the electrolytes. The specific capacitance, Ce quoted in this work for each of the electrode pairs, was calculated from: $\mathrm{Ce}=2\left[\left(i_{\mathrm{c}}+i_{\mathrm{a}}\right) / 2\right] / s / W$, where $i_{\mathrm{c}}$ and $i_{\mathrm{a}}$ are, respectively, the currents at $0.0 \mathrm{~V}$ during the cathodic and anodic sweeps, $s$ the sweep rate, $W$ the weight of the total carbon materials in each electrode. The factor of 2 accounts for the fact that each of the electrodes forms one capacitor at the interface, and hence, there are two serial capacitors in one cell.

\section{Results and discussion}

Some microstructural properties of the two carbonaceous materials used in the present work are listed in Table 1. The activated carbon, which hereafter will be referred to as activated carbon (AC), is a locally supplied carbonaceous material that was originally designed for use in water treatment. It has a BET surface area of $1420 \mathrm{~m}^{2} \mathrm{~g}^{-1}$ which is about seven times that of the $\mathrm{CB}$ component (VULCAN ${ }^{\circledR}$ XC72, Cabot Corp., USA). In contrast, the CB has a greater degree of graphitisation, as clearly indicated by $\mathrm{X}$-ray diffraction (XRD) patterns (Fig. 1). In spite of its very large surface area, the AC alone exhibits little capacitance (curve 1, Fig. 2), presumably due to its poor electronic conductivity. On the other hand, the $\mathrm{CB}$ exhibits a specific capacitance of 23.5 and $14.2 \mathrm{~F} \mathrm{~g}^{-1}$ in $1 \mathrm{M} \mathrm{KOH}_{(\mathrm{aq})}$ and $1 \mathrm{M}$ $\mathrm{Na}_{2} \mathrm{SO}_{4(\mathrm{aq})}$, respectively, at a sweep rate of $20 \mathrm{mV} \mathrm{s}^{-1}$ (Fig. 2).

Composite electrodes containing a CB gravimetric content, [CB], of $10,25,50$, or $75 \mathrm{wt} . \%$, respectively, were examined. $\mathrm{CV}$ analysis shows that, in either electrolyte, the composite electrodes exhibit anodic and cathodic traces parallel to each other, characteristic of a capacitor (e.g. curves 3 and 4, Fig. 2). A maximum capacitance is found
Table 1

Microstructural properties of tested carbonaceous materials

\begin{tabular}{|c|c|c|}
\hline Sample type & $\begin{array}{l}\text { Activated carbon } \\
\text { (AC) }\end{array}$ & $\begin{array}{l}\text { Carbon black } \\
\text { (CB) }\end{array}$ \\
\hline BET surface area $\left(\mathrm{m}^{2} \mathrm{~g}^{-1}\right)^{\mathrm{a}}$ & 1420 & 220 \\
\hline Average pore size by BET (nm) & 3.6 & 6.1 \\
\hline Pore volume $\left(\mathrm{cm}^{3} \mathrm{~g}^{-1}\right)$ & 1.2 & 0.34 \\
\hline Average crystallite size $(\mathrm{nm})$ & 0.7 & 2.1 \\
\hline
\end{tabular}

${ }^{\mathrm{a}}$ BET analysis was carried by using $\mathrm{N}_{2}$ adsorption.

${ }^{\mathrm{b}}$ Average crystallite size is calculated using Debye-Scherrer equation based on full width at half-maximum intensity of X-ray diffraction (002) reflection of graphite.

at $[\mathrm{CB}]=25 \mathrm{wt} . \%$ for each sweep rate in the range 20 $200 \mathrm{mV} \mathrm{s}^{-1}$ (Fig. 3a and b), irrespective of the electrolyte. The maximum specific capacitances are 108 and $75 \mathrm{~F} \mathrm{~g}^{-1}$ for $1 \mathrm{M} \mathrm{KOH}_{(\mathrm{aq})}$ and $1 \mathrm{M} \mathrm{Na}_{2} \mathrm{SO}_{4(\mathrm{aq})}$, respectively, at a sweep rate of $20 \mathrm{mV} \mathrm{s}^{-1}$.

Plots of capacitance versus CV sweep rate are given in Fig. 4. For the pure CB electrode, the specific capacitance declines $<20 \%$ as the $\mathrm{CV}$ sweep rate increasing by a factor of 10, from 20 to $200 \mathrm{mV} \mathrm{s}^{-1}$ (Fig. 4a and b). This suggests high electronic and ionic conductivities; the latter is due to the large pore size of CB (Table 1). On the other hand, for the composite electrodes, the capacitance declines much more rapidly, at a rate (indicated by the slope of the declining curve) that depends strongly on [CB] (Fig. 4a and b). The declining rate is highest for $[\mathrm{CB}]=10 \mathrm{wt} . \%$ and levels off for $[\mathrm{CB}] \geq 25 \mathrm{wt} . \%$. When the capacitance data of the composite electrodes are subtracted by the amount equal to the product of the capacitance of pure $\mathrm{CB}$ at the corresponding sweep rate and its content, and then re-plotted, the 'CB-subtracted' declining curves (Fig. 5a and b) for $[\mathrm{CB}] \geq 25 \mathrm{wt}$.\% overlap with one another but are distinctly different from, that for $[\mathrm{CB}]=10 \mathrm{wt} . \%$.

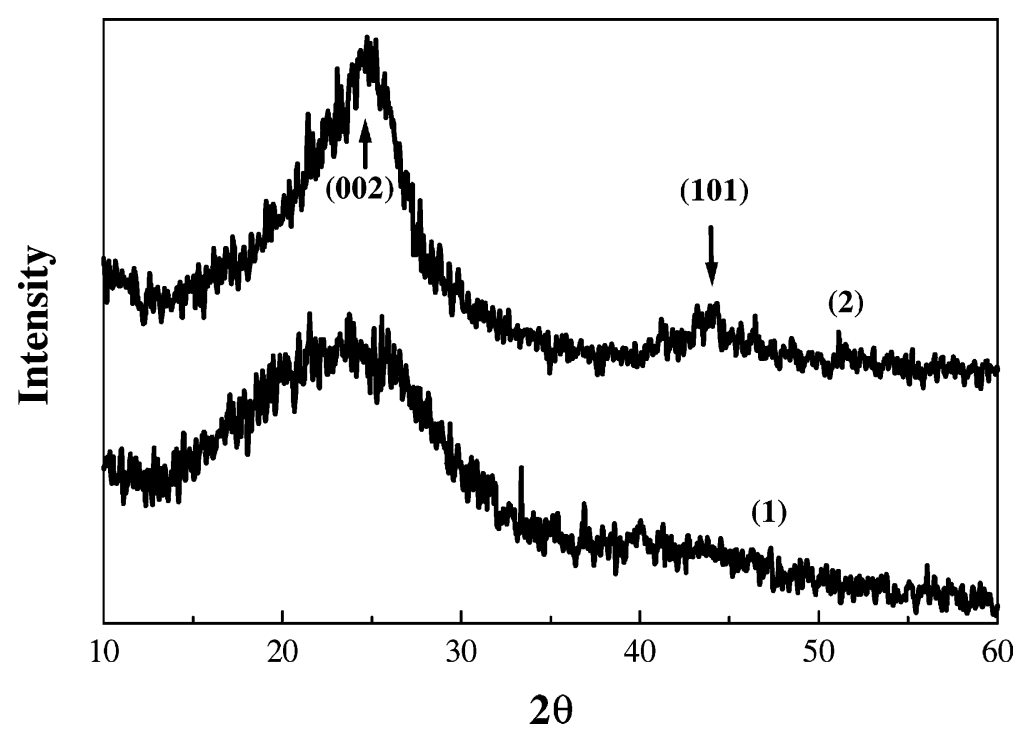

Fig. 1. XRD patterns of (1) activated carbon and (2) carbon black components of carbon composite electrodes, showing varied degree of graphitisation. Marked reflections for graphite. 


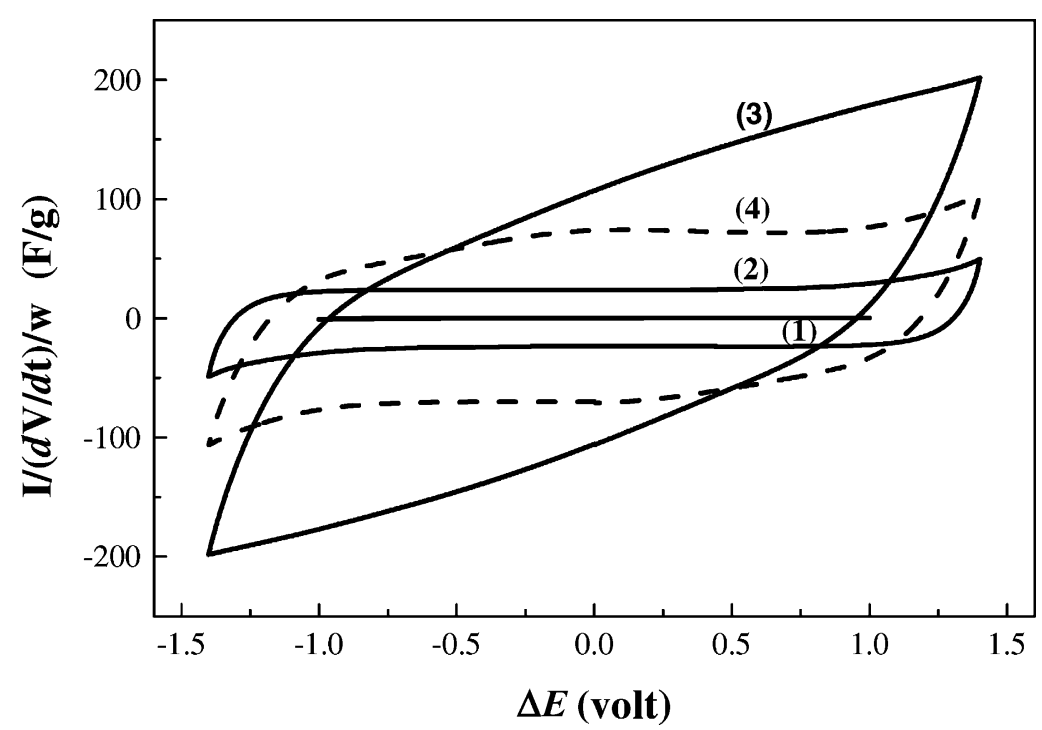

Fig. 2. Voltammograms acquired at a sweep rate of $20 \mathrm{mV} \mathrm{s}^{-1}$ for (1) activated carbon, (2) carbon black in $1 \mathrm{M} \mathrm{KOH}_{(\mathrm{aq})}$, (3) composite electrodes containing 25 wt.\% carbon black in $1 \mathrm{M} \mathrm{KOH}_{(\mathrm{aq})}$, (4) same composite electrodes in $1 \mathrm{M} \mathrm{Na}_{2} \mathrm{SO}_{4(\mathrm{aq})}$.

From the above experimental results, it is proposed that the optimum [CB] for maximum capacitance arises mainly from the conductivity percolation of the $\mathrm{CB}$ particles. With $[\mathrm{CB}]<25 \mathrm{wt} . \%$, the CB particles do not percolate throughout the entire electrode and only a portion of the AC particles
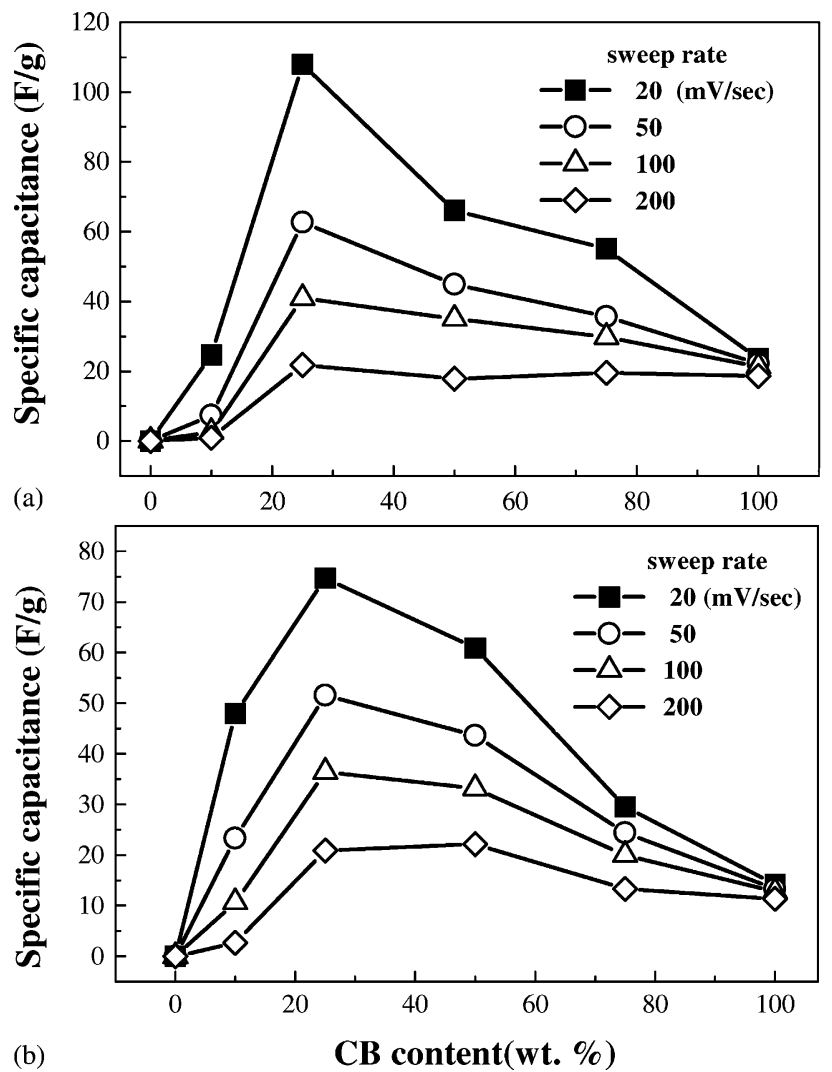

Fig. 3. Effect of electrode composition on specific capacitance for composite electrodes in (a) $1 \mathrm{M} \mathrm{KOH}_{(\mathrm{aq})}$ and (b) $1 \mathrm{M} \mathrm{Na}_{2} \mathrm{SO}_{4(\mathrm{aq})}$. contribute to the overall capacitance. In this case, the overall capacitance increases with increasing $[\mathrm{CB}]$. When percolation is achieved with $[\mathrm{CB}] \geq 25 \mathrm{wt} . \%$, however, the overall capacitance decreases with increasing $[\mathrm{CB}]$ due to reduction in the total surface area, as CB has a much smaller specific
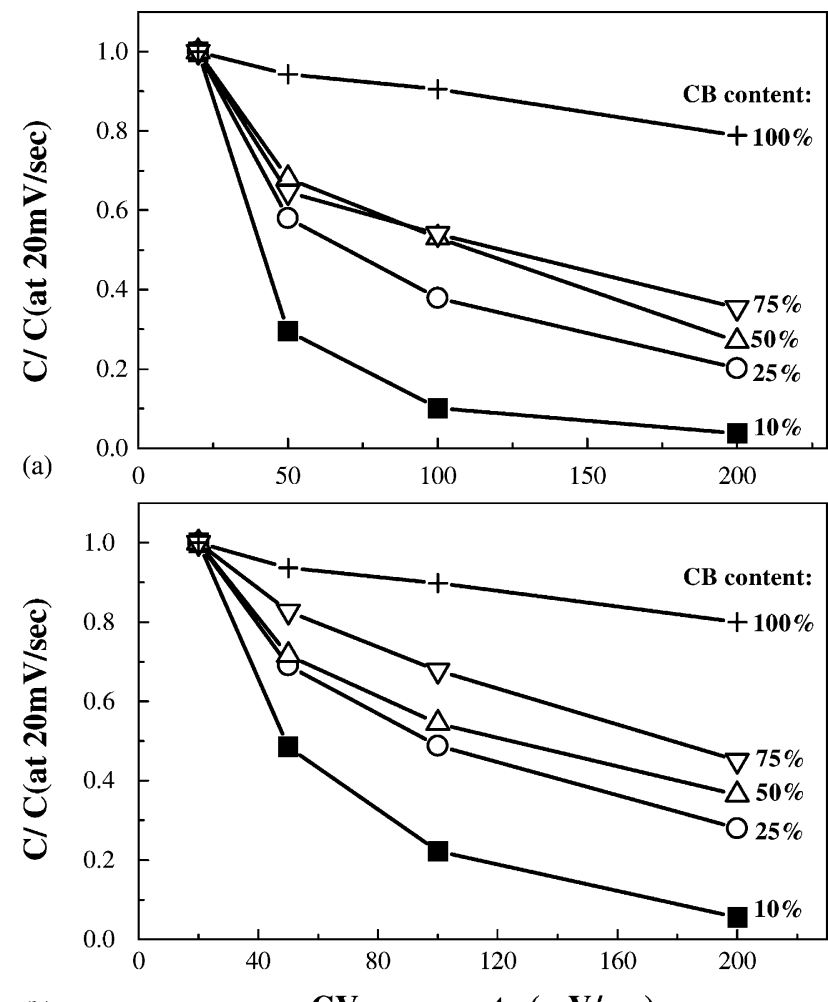

(b)

Fig. 4. Effect of $\mathrm{CV}$ sweep rate on specific capacitance for composite electrodes in (a) $1 \mathrm{M} \mathrm{KOH}_{(\mathrm{aq})}$ and (b) $1 \mathrm{M} \mathrm{Na}_{2} \mathrm{SO}_{4(\mathrm{aq})}$. All capacitance data have been divided by those acquired at $20 \mathrm{mV} \mathrm{s}^{-1}$ for corresponding electrode composition and electrolyte. 


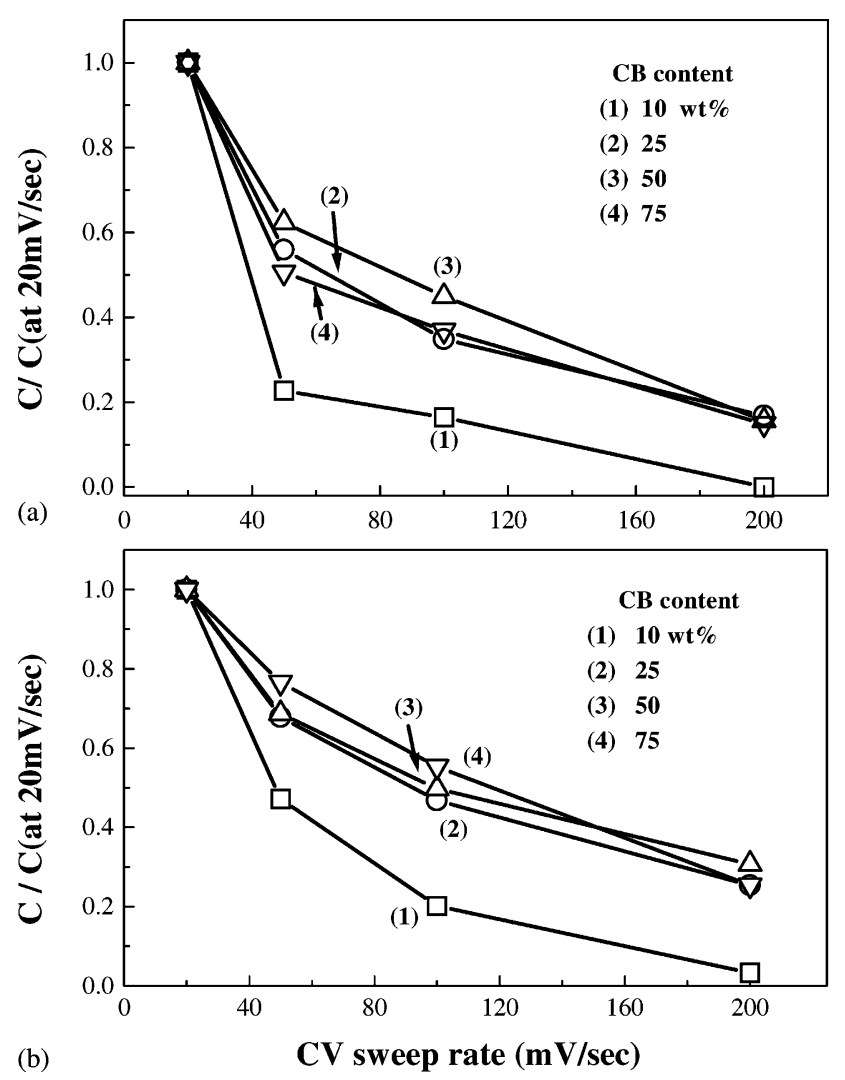

Fig. 5. 'CB-subtracted' declining curves for composite electrodes in (a) $1 \mathrm{M} \mathrm{KOH}_{(\mathrm{aq})}$ and (b) $1 \mathrm{M} \mathrm{Na}_{2} \mathrm{SO}_{4(\mathrm{aq})}$. All capacitance data have first been subtracted by amount equal to product of capacitance of pure carbon black (CB) and its weight fraction in corresponding electrode, and then divided by 'subtracted' capacitance for $20 \mathrm{mV} \mathrm{s}^{-1}$.

surface area than AC. Based on BET pore volume data (Table 1), CB has a density about twice that of AC. This translates the observed optimum CB gravimetric content, viz. $25 \mathrm{wt} . \%$, into an optimum volumetric fraction of $14.3 \mathrm{vol} \%$, which is actually close to the theoretical threshold of the percolation volume fraction ( $\sim 16 \mathrm{vol} . \%)$ for equalsized spherical particles [12]. The small difference may be due to several factors, such as variations in particle size and shape as well as the presence of voids and binder material.

The suggested concept of electronic conductivity percolation is also consistent with the observed rate-dependence of the capacitance shown in Figs. 4 and 5. This ratedependence arises mainly from two resistances, namely, one associated with the electronic conduction of the electrode and the other with the ionic conduction on the electrolyte side within pores of the carbon particles. It is suggested that for $[\mathrm{CB}]=10 \mathrm{wt} . \%$, i.e. below the percolation threshold, both resistances contribute to the decline in capacitance, and hence, the rate of decline is greater than for the other electrodes. For [CB] above the threshold, the electrolyte ionic resistance becomes dominant. This explains why all the composite electrodes with $[\mathrm{CB}] \geq 25 \mathrm{wt}$.\% show almost the same declining behaviour after being corrected for the CB contribution (Fig. 5a and b). The 'subtracted' declining curves in these cases account only for the effect of ionic resistance.

\section{Conclusions}

Conductivity percolation is found to play a critical role in determining the electrochemical capacitive behaviour of a carbon-carbon composite electrode which comprises a non-conductive activated carbon of large surface area and a conductive $\mathrm{CB}$ of small surface area. The capacitance is limited by electronic resistance on the electrode side when the content of CB is below the threshold value, but is limited by surface area as the threshold is exceeded. Maximum capacitance can be obtained with a composition close to the percolation threshold of the conductive phase.

\section{Acknowledgements}

This work was supported by the National Science Council of the Republic of China under contract no. NSC 90-2214-E002-009.

\section{References}

[1] G. Salitra, A. Soffer, L. Eliad, Y. Cohen, D. Aurbach, J. Electrochem. Soc. 147 (2000) 2486.

[2] L. Bonnefoi, P. Simon, J.F. Fauvarque, C. Sarrazin, J.F. Sarrau, A. Dugast, J. Power Sources 80 (1999) 149.

[3] C. Lin, J.A. Ritter, B.N. Popov, J. Electrochem. Soc. 146 (1999) 3639.

[4] D. Qu, H. Shi, J. Power Sources 74 (1998) 99.

[5] J.C. Farmer, D.V. Fix, G.V. Mack, R.W. Pekala, J.F. Poco, J. Electrochem. Soc. 143 (1996) 159.

[6] T. Monuna, X. Liu, T. Osaka, Y. Ushio, Y. Sawada, J. Power Sources 60 (1996) 249

[7] J. Koresh, A. Saffer, J. Electrochem. Soc. 124 (1977) 1379.

[8] M. Ramani, B.S. Haran, R.E. White, B.N. Popov, J. Electrochem. Soc. 148 (2001) 374.

[9] J.P. Zheng, Electrochem. Solid-State Lett. 2 (1999) 359.

[10] J.P. Zheng, T.R. Jow, J. Power Sources 62 (1996) 155.

[11] S. Ergun, in: P.L. Walker Jr. (Ed.), Chemistry and Physics of Carbon, Vol. 3, Marcel Dekker, New York, 1968, pp. 211-288.

[12] R. Zallen, The Physics of Amorphous Solids, Wiley, New York, 1983 (Chapter 4). 